\title{
Preliminary Aging Assessment of Nuclear Air-Treatment and Cooling System Fans
}

W. K. Winegardner

July 1995

Prepared for

Division of Engineering

Office of Nuclear Regulatory Research

U.S. Nuclear Regulatory Commission

under a Related Services Agreement with the

U.S. Department of Energy

Contract DE-AC06-76RLO 1830

NRC FIN B2911

Pacific Northwest Laboratory Operated for the U.S. Department of Energy

by Battelle Memorial Institute 


\title{
DISCLAIMER
}

This report was prepared as an account of work sponsored by an agency of the United States Government. Neither the United States Government nor any agency thereof, nor Battelle Memorial Institute, nor any of their employees, makes any warranty, expressed or implied, or assumes any legal liability or responsibility for the accuracy, completeness, or usefulness of any information, apparatus, product, or process disclosed, or represents that its use would not infringe privately owned rights. Reference herein to any specific commercial product, process, or service by trade name, trademark, manufacturer, or otherwise does not necessarily constitute or imply its endorsement, recommendation, or favoring by the United States Government or any agency thereof, or Battelle Memorial Institute. The views and opinions of authors expressed herein do not necessarily state or reflect those of the United States Government or any agency thereof.

\author{
PACIFIC NORTHWEST LABORATORY \\ operated by \\ BATTELLE MEMORIAL INSTITUTE \\ for the \\ UNITED STATES DEPARTMENT OF ENERGY \\ under Contract DE-ACO6-76RLO 1830
}

Printed in the United States of America

Available to DOE and DOE contractors from the

Office of Scientific and Technical Information, P.O. Box 62, Oak Ridge, TN 37831; prices available from (615) 576-8401. FTS 626-8401.

Available to the public from the National Technical Information Service, U.S. Department of Commerce, 5285 Port Royal Rd., Springfield, VA 22161. 


\section{Preliminary Aging Assessment of Nuclear Air-Treatment and Cooling System Fans}

W. K. Winegardner

July 1995

Prepared for

Division of Engineering

Office of Nuclear Regulatory Research

U.S. Nuclear Regulatory Commission

under a Related Services Agreement with the

U.S. Department of Energy

Contract DE-AC06-76RLO 1830

NRC FIN B2911

Pacific Northwest Laboratory

Richland, Washington 99352 



\begin{abstract}
A preliminary aging assessment of the fans used in nuclear air treatment and cooling systems was performed by the Pacific Northwest Laboratory as part of the U.S. Nuclear Regulatory Commission's Nuclear Plant Aging Research Program. Details from guides and standards for the design, testing, and installation of fans; results of failure surveys; and information concerning stressors, related aging mechanisms, and inspection, surveillance, and monitoring methods (ISMM) were compiled. Failure surveys suggest that about half of the failures reported for fans are primarily associated with aging. Aging mechanisms associated with the various fan components and resulting from mechanical, thermal, and environmental stressors include wear, fatigue, corrosion, and erosion of metals and the deterioration of belts and lubricants. A bearing is the component most frequently linked to fan failure. The assessment also suggests that ISMM that will detect irregularities arising from improper lubrication, cooling, alignment, and balance of the various components should aid in counteracting many of the aging effects that could impair fan performance. An expanded program, to define and evaluate the adequacy of current ISMM and maintenance practices and to include a documented Phase I aging assessment, is recommended.
\end{abstract}




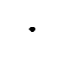

. 


\section{Summary}

This report presents a preliminary aging assessment of the fans used in nuclear air treatment and cooling systems. The work was performed by the Pacific Northwest Laboratory as part of the U.S. Nuclear Regulatory Commission's Nuclear Plant Aging Research Program. Details from guides and standards for the design, testing, and installation of fans; results of failure surveys; and information concerning stressors, related aging mechanisms, and inspection, surveillance, and monitoring methods (ISMM) are included in the report.

Fans are used to recirculate, supply, and/or exhaust large quantities of air in several nuclear power plant air-treatment (cleaning) and air-cooling systems. Failure of these systems can impact both plant and public safety. Fans are used to direct air containing radioactive contaminants through the filters and adorbers that can be the last barrier to the release of radioactivity to the public following an accident. Furthermore, fans are components of systems needed to ensure the safe shutdown of the plant or allow equipment to be serviced. Satisfactory performance of certain airtreatment systems is essential to ensure control room habitability. Fans are also components of air-treatment and cooling systems that provide a safe environment for personnel and a controlled environment for equipment during normal operations.

The results of the preliminary aging assessment of fans suggest that aging degradation is important when considering fan failure. The Code on Nuclear Air and Gas Treatment addresses the consideration of aging as part of fan design. Failure surveys containing information on aging and wear effects imply that about half of the failures reported for fans are primarily associated with aging. Aging mechanisms associated with the various fan components and resulting from mechanical, thermal, and environmental stressors include wear, fatigue, corrosion, and erosion of metals; and the deterioration and degradation of belts and lubricants. A bearing is the component most frequently linked to fan failure. The assessment also suggests that ISMM that will detect irregularities arising from improper lubrication, cooling, alignment, and balance of the various components should aid in counteracting many of the aging effects that could impair fan performance.

The observation that aging degradation appears to be an important factor in fan failure, reinforced by the fact that failure can impact both plant and public safety, suggests the need for further study. The results of an expanded investigation, an effort that would focus on identifying and evaluating current ISMM and maintenance practices, would ultimately be combined with those of this preliminary study in the form of a published Phase I interim aging assessment. 



\section{Acronyms and Abbreviations}

$\begin{array}{ll}\text { AMCA } & \text { Air Movement and Control Association } \\ \text { ANSI } & \text { American National Standards Institute } \\ \text { ASME } & \text { American Society of Mechanical Engineers } \\ \text { CFR } & \text { Code of Federal Regulations } \\ \text { CTF } & \text { Containment Fan System } \\ \text { CTIS } & \text { Containment Isolation System } \\ \text { DOE } & \text { U.S. Department of Energy } \\ \text { EPRI } & \text { Electric Power Research Institute } \\ \text { ESF } & \text { engineered safety feature } \\ \text { HEPA } & \text { high-efficiency particulate air } \\ \text { ISMM } & \text { inspection, surveillance, and monitoring methods } \\ \text { LER } & \text { Licensee Event Report } \\ \text { NPRDS } & \text { Nuclear Plant Reliability Data System } \\ \text { NRC } & \text { U.S. Nuclear Regulatory Commission } \\ \text { RBC } & \text { Reactor Building Cooling System } \\ \text { RG } & \text { Regulatory Guide } \\ \text { 1E } & \text { 1E Electrical Power Distribution System } \\ \end{array}$





\section{Contents}

Abstract $\ldots \ldots \ldots \ldots \ldots \ldots \ldots \ldots \ldots \ldots \ldots \ldots \ldots \ldots \ldots \ldots \ldots \ldots$ iii

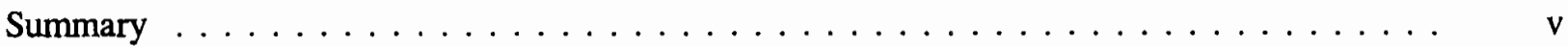

Acronyms and Abbreviations $\ldots \ldots \ldots \ldots \ldots \ldots \ldots \ldots \ldots$ vii

1.0 Introduction and Background $\ldots \ldots \ldots \ldots \ldots \ldots \ldots \ldots \ldots \ldots \ldots$

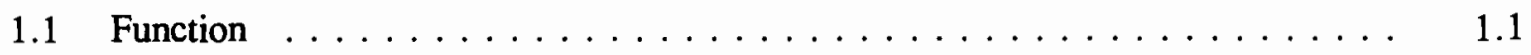

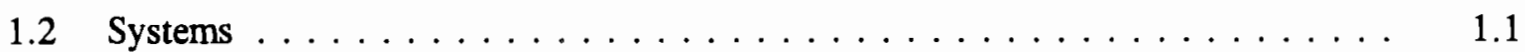

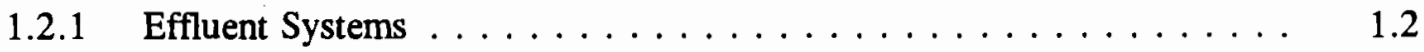

1.2.2 Fan Cooler Systems . . . . . . . . . . . . . . . 1.3

1.2 .3 Other Systems $\ldots \ldots \ldots \ldots \ldots \ldots \ldots \ldots \ldots \ldots \ldots$

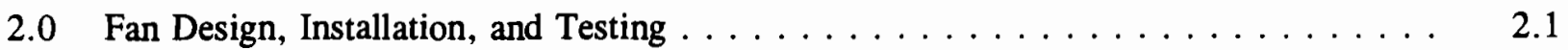

2.1 Guides and Standards $\ldots \ldots \ldots \ldots \ldots \ldots \ldots \ldots \ldots \ldots$

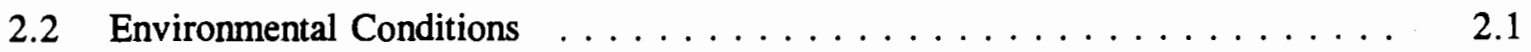

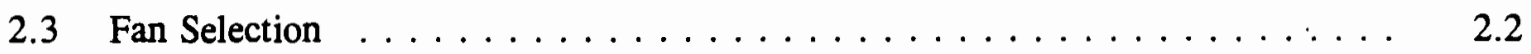

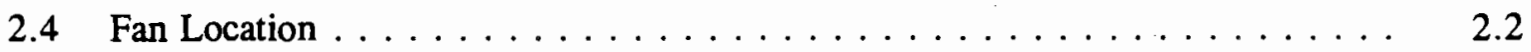

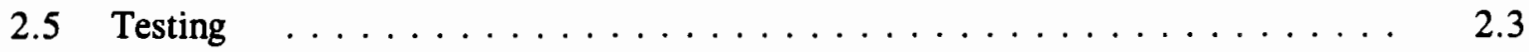

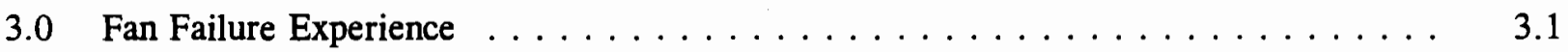

3.1 Survey of Light-water Reactor Safety System and Component Aging Failure $\ldots \ldots \ldots \ldots \ldots \ldots \ldots \ldots \ldots \ldots \ldots \ldots$

3.2 Aging Assessment of Light-water Reactor Fan Cooler Systems . . . . . . . . 3.2

3.3 Failure Cause Analysis of Fans In Fossil-fuel Plants $\ldots \ldots \ldots \ldots \ldots \ldots$

3.4 DOE Experience With Aging Fans . . . . . . . . . . . . . . . 3.3

4.0 Fan Stressors, Aging Mechanisms, and Inspection, Surveillance, and Monitoring Methods

4.1 Stressors and Aging Mechanisms $\ldots \ldots \ldots \ldots \ldots \ldots \ldots \ldots$ 
4.2 Inspection, Surveillance, and Monitoring Methods $\ldots \ldots \ldots \ldots \ldots$

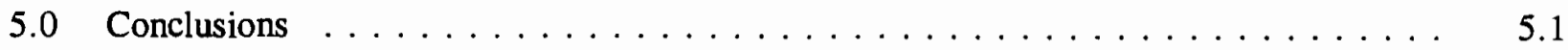

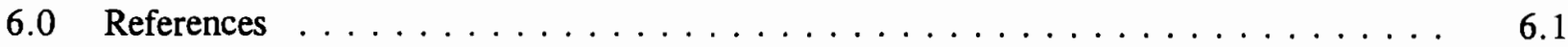




\section{Figures}

1.1. Centrifugal and Axial Fan Configurations $\ldots \ldots \ldots \ldots \ldots \ldots \ldots \ldots$

\section{Tables}

3.1. Total,Blower, and Blower Aging Failures in Electrical Power Distribution, Containment Fan and Isolation, and Reactor Building Cooling Systems

4.1. Stressors, Aging Mechanisms, Aging Degradation, and Degradation Detection Methods for Selected Fan Components 


\subsection{Introduction and Background}

This report presents the results of a preliminary aging assessment of the fans used in nuclear airtreatment and cooling systems. The work was performed by Pacific Northwest Laboratory ${ }^{(a)}$ as part of the U.S. Nuclear Regulatory Commission (NRC) Nuclear Plant Aging Research Program (NRC 1991). Details from guides and standards for the design, testing, and installation of fans; results of failure surveys; and information concerning stressors, related aging mechanisms, and inspection, surveillance, and monitoring methods (ISMM) are included in the report.

\subsection{Function}

Fans recirculate, supply, or exhaust air by adding enough energy to initiate motion and overcome resistance to flow. Usually a fan consists of a rotating bladed wheel or propeller that performs the work and a housing to direct the air discharged by the rotor. There are basically two different types of fans: centrifugal and axial (see Figure 1.1). In the centrifugal type, air is accelerated radially outward in the rotating wheel from the base to the tip of the blades. The rotor or bladed wheel is surrounded by a scroll-type casing or housing. Air enters the casing via inlets that are concentric with the rotating shaft. In the case of the axial fan, air is accelerated parallel to the shaft.

\subsection{Systems}

Fans are used to recirculate, supply, and/or exhaust large quantities of air in several nuclear power plant air-treatment (cleaning) and air-cooling systems. Failure of these systems can impact both plant and public safety. Fans are used to direct air containing radioactive contaminants through other system components, namely the filters and absorbers, which can be the last barrier to the release of radioactivity to the public following an accident. In addition, fans are components of systems needed to ensure the safe shutdown of the plant or to allow equipment to be serviced. Satisfactory performance of certain air-treatment systems is essential to ensure control room habitability. Fans are also components of air-treatment and cooling systems that provide a safe environment for personnel and a controlled environment for equipment during normal operations.

(a) Pacific Northwest Laboratory is operated for the U.S. Department of Energy by Battelle Memorial Institute under Contract DE-AC06-76RLO 1830. 

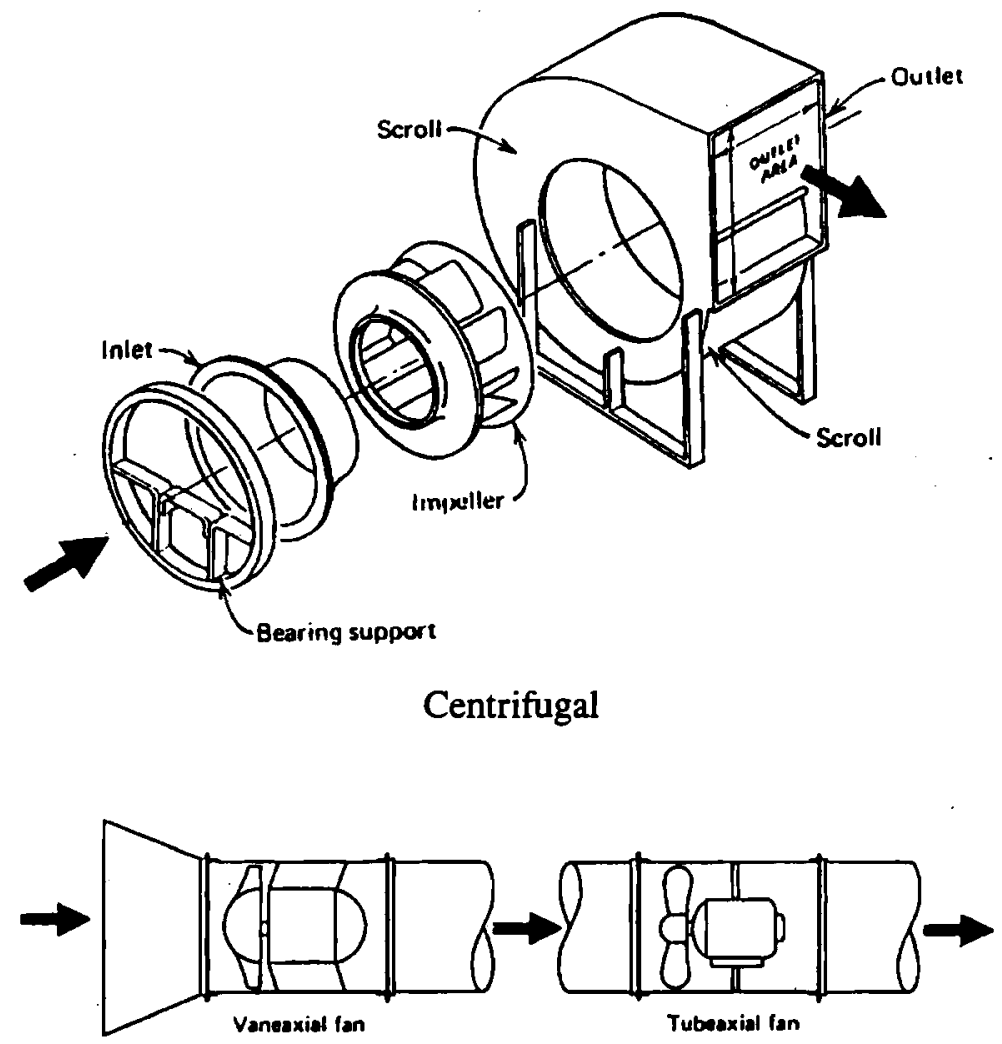

Axial

Figure 1.1. Centrifugal and Axial Fan Configurations

\subsubsection{Effluent Systems}

In once-through effluent air-treatment systems, fans are used to direct up to approximately $14.23 / \mathrm{s}$ $\left(30,000 \mathrm{ft}^{3} / \mathrm{min}\right)$ of air through radionuclide retention components; namely, the high-efficiency particulate air (HEPA) filters and the activated gas adsorption units (charcoal absorbers). Multiple trains are recommended for larger flow rates (NRC 1978, 1979). When the filters and charcoal absorbers of these single-pass systems are located in a clean or protected space (which is usual), fans are typically installed downstream of the two retention components and often close to the discharge point (vent or stack). The downstream fan location is used to maintain the filter housing and as much of the connecting ductwork as possible under a negative pressure. Outleakage of contaminants is minimized and infiltration through the fan shaft will be from a clean space. Furthermore, a fan location close to the exhaust point is the "cleanest" part of the system. The lower contamination levels make it easier to maintain the units. 


\subsubsection{Fan Cooler Systems}

In the case of containment air-cooling (fan-cooler) systems in nuclear plants, a fan is used to direct containment air over cooling coils. In general, these systems are used to maintain a suitable atmosphere for equipment located within containment. In some plants the systems are also designed to reduce containment temperature and pressure during accidents. Centrifugal and axial fans are typically used for older and newer plants, respectively (Lofaro and Subudhi 1993). Fan-cooler system design information for several plants has been summarized by Lofaro and Subudhi, along with plant-specific details for a system "... designed to recirculate and cool the containment atmosphere in the event of an accident.... During normal operation [to remove the normal heat loss from equipment and piping], the flow sequence through each [of five] air handling unit is as follows: inlet dampers, roughing filters, cooling coils, [centrifugal] fan, discharge header. During post-accident operation, air is drawn through a moisture separator, ... HEPA filter section and cooling coils.... The fans are designed to supply $110,000 \mathrm{cfm}$ during normal operation, and 47,000 cfm during accident operation." (a)

\subsubsection{Other Systems}

Fans are also key components of the control room ventilation systems designed to ensure habitability during both normal and accident conditions. Fans move air to cool rooms housing safety-related equipment (e.g., emergency cooling water pumps, engineered safety feature [ESF] equipment, and battery and relay rooms). A final example of the use of fans is to recirculate air from the lower containment volume into the upper volume via the ice compartments of an ice condenser containment system. Each of two fans is rated at $18.9 \mathrm{~m}^{3} / \mathrm{s}\left(40,000 \mathrm{ft}^{3} / \mathrm{min}\right)$.

(a) 52.4 and $22.2 \mathrm{~m}^{3} / \mathrm{s}$, respectively. 
- 


\subsection{Fan Design, Installation, and Testing}

Selected information concerning fan design, installation, and testing is presented in this section. Details concerning guides and standards, environmental conditions, fan selection and location with respect to other air-treatment system components, and testing are included.

\subsection{Guides and Standards}

Nuclear Regulatory Commission Regulatory Guides 1.52 and 1.140 present methods for implementing regulations in Appendix A to 10 CFR Part 50 with regard to the design, testing, and maintenance criteria for ESF and normal ventilation exhaust air-treatment systems (NRC 1978, NRC 1979, 10 CFR 50). Both of the regulatory guides (RGs) state that the system fan should be designed, constructed, and tested in accordance with appropriate sections of American National Standards Institute (ANSI) N509-1976. Other applicable documents listed in the latest revision of this ANSI standard, American Society of Mechanical Engineers (ASME) N509-1989, include the ASME/ANSI Code on Nuclear Air and Gas Treatment, Section BA, "Fans and Blowers," and the Air Movement and Control Association (AMCA) Fan Application Manual (ASME 1989a, ASME/ANSI 1988, AMCA 1985). Section BA of the Code includes articles on materials; design; inspection and testing; fabrication and installation of centrifugal and axial fans; packaging, shipping, and storage; quality assurance; and nameplates and operating and maintenance manuals. Selected information from these documents is presented in the following sections. Before proceeding it should be noted that there is no intent to imply that all of the information presented or referenced in the ASME/ANSI or AMCA documents has been evaluated by the NRC for applicability or acceptability. Furthermore, the use of the term "requirement" in conjunction with these documents does not necessarily mean that a particular requirement has been accepted by the NRC.

\subsection{Environmental Conditions}

According to RG 1.52, "...all components of ESF atmosphere cleanup systems need to be designed for reliable performance under accident conditions" (NRC 1978). Consideration of aging as part of fan design is addressed in Article BA-4000, "Design," of the Code on Nuclear Air and Gas Treatment (ASME/ANSI 1988). More specifically, it is stated that "The following aging mechanisms affecting life expectancy shall be considered as a minimum:

1. radiation

2. temperature variation range

3. pressure variation range

4. corrosive chemicals and moisture conditions

5. erosive particles in air streams

6. duty cycles." 
In the aging terminology that is commonly used for nuclear power plants, the above mechanisms are more appropriately called "stressors"; i.e., agents that stem from service conditions that can produce immediate or aging degradation of a fan (EPRI 1992). Vibration is another potential major stressor, and the dynamic balancing of fan wheels is required before fan assembly. Final balancing after fan installation is also required. The maximum allowable double-amplitude radial displacement measured on the bearing caps and fan housing at the designated fan speed is specified for centrifugal and axial fans, respectively, in Article BA-4000.

\subsection{Fan Selection}

The fan must provide sufficient energy to overcome resistance to flow. As a result, fans are selected by using detailed system pressure drop calculations in combination with fan performance curves. The pressure drop calculations must include consideration of factors such as losses associated with flow through dirty as well as clean filters, ductwork, and the various entrances and exits involved. Both system characteristics and fan performance are best represented in graphical form, as plots of system resistance versus airflow and of pressure capability versus airflow, respectively. The airflow that the fan can deliver is then defined by the intersection of the system resistance and fan performance plots or curves.

Dust loading can significantly increase the flow resistance of filters, particularly HEPA filters. Before a filter is replaced, flow resistance values may be four or five times greater than those for newly installed or clean filters. Therefore, fans whose performance curves have a steep head characteristic are frequently used in air-cleaning or air-treatment systems when filtration is involved. A steep head characteristic limits effects of system resistance and can minimize the change in flow rate associated with increasing filter pressure drop. Additional information about fan-system interactions is presented in the AMCA Fan Application Manual (AMCA 1985) and by Burchsted, Kahn, and Fuller (1976).

With respect to fan-system capacity control, the Code on Nuclear Air and Gas Treatment notes that "The use of an outlet or inlet damper to control an axial fan should not be permitted unless loading conditions are completely evaluated...the acceptable methods to change the fan performance curve of a fan used on nuclear safety-related systems are variable inlet vanes on a centrifugal fan and blade angle change on an axial fan" (ASME/ANSI 1988).

\subsection{Fan Location}

The physical location and arrangement of the components of air-treatment systems, including fans, are discussed in the ASME standard (1989a). General guidance is provided for effluent (oncethrough), habitability, and recirculating systems. For example, a downstream fan location is recommended for effluent systems where the filters and absorbers are located in a clean interspace. As stated earlier, the downstream fan location maintains the air-cleaning components under negative pressure and minimizes the outleakage of contaminants. Schematics are included in Appendix B of ASME (1989a) as examples of combinations and locations of fans and filters and absorbers that will promote contamination control/confinement by single-pass and recirculating system configurations. 


\subsection{Testing}

Performance and mechanical tests are specified in ASME/ANSI (1988). Fan performance tests include the measurements of flow rate, pressure, power, and fan speed. Testing in accordance with AMCA $210^{\text {(a) }}$ is specified by both ASME (1989a) and ASME/ANSI (1988) (AMCA/ASHRAE 1986). Mechanical tests include overspeed, leakage (housing and shaft), vibration, mechanical running, and seismic tests. Acceptance tests for installed fans (after completion of initial construction or major system modification or repair) are defined by ASME (1989b). Capacity tests, "...to verify that the design airflow can be achieved with the fan as furnished, under actual field conditions at maximum and minimum filter pressure drop," are included.

(a) The purpose of the AMCA standard "...is to establish uniform methods for laboratory testing of fans...to determine performance in terms of flow rate, pressure, power, air density, speed of rotation, and efficiency, for rating or guarantee purposes." 


\subsection{Fan .Failure Experience}

Three failure surveys were found that contained information about aging and wear effects on fans and blowers. Two of the surveys were associated with nuclear plant systems; one presented information solely related to fans in fossil-fuel-fired plants. The U.S. Department of Energy (DOE) experience with aging fans is also discussed briefly.

\subsection{Survey of Light-water Reactor Safety System and Component Aging Failure}

"Blowers" were included within the boundaries of 4 of the 15 systems studied in an aging failure survey of light-water reactor safety systems and components (Meale and Satterwhite 1988). The four systems were the Class 1E Electrical Power Distribution System (1E); Containment Fan System (CTF); Containment Isolation System (CTIS); and Reactor Building Cooling System (RBC). The blower listed for the $1 \mathrm{E}$ system is believed to be the compressor of the starting air subsystem for emergency diesel generators. This $1 \mathrm{E}$ system is a standby system; the remaining three are normally operating systems. Information presented by Meale and Satterwhite that is ultimately relatable to "blower" aging failures is summarized in Table 3.1.

Review of Table 3.1 reveals that for the three normally operating systems, CTF, CTIS, and RBC, about half of the blower failures were attributed to aging. However, only about $2 \%$ of the total number of failures were associated with blower aging. It should perhaps be noted that the two highest component aging failure percentages listed for the CTIS were associated with valves and valve operators: $28 \%$ and $12 \%$, respectively. Aging failure of valves also ranked highest for 11 other systems, including the RBC system $(9 \%)$. The $28 \%$ listed for CTIS system valves was also the highest value reported. The highest component aging failure percentages (5\% to 6\% percent) for the remaining two systems, CTF and class $1 \mathrm{E}$ systems, were associated with circuit breakers and, notably, blowers (compressors).

Table 3.1. Total, Blower, and Blower Aging Failures in Electrical Power Distribution, Containment Fan and Isolation, and Reactor Building Cooling Systems

\begin{tabular}{lrrrr} 
& \multicolumn{3}{c}{ Failures } \\
\cline { 3 - 5 } System & \multicolumn{1}{c}{ Total } & & Blower & $\begin{array}{r}\text { Blower } \\
\text { Aging }\end{array}$ \\
\cline { 5 - 5 } \cline { 5 - 5 } 1E & & & \\
CTF & 2259 & 215 & 134 \\
CTIS & 318 & 28 & 13 \\
RBC & 926 & 16 & 9 \\
& 65 & 7 & 2
\end{tabular}




\subsection{Aging Assessment of Light-water Reactor Fan Cooler Systems}

Fans or blowers were included within the boundaries of one of the two systems evaluated in a survey by Lofaro and Subudhi (1993), an aging assessment of containment cooling systems of commercial nuclear power plants. More specifically, the fans or blowers were studied as a component of fan cooler systems and, as indicated earlier, are used to direct air over cooling coils. Information from national databases as well as plant-specific data was used in the aging assessment. Both data sources indicate a definite relationship between system failures and aging degradation.

Databases included the Nuclear Plant Reliability Data System (NPRDS) and Licensee Event Reports (LERs) for the 51/2-year period from January 1986 to June 1991 and the $61 / 2$-year period from January 1985 to June 1991, respectively. Assessment of the NPRDS and LER databases revealed that over $50 \%$ and $40 \%$, respectively, of the system failures reported were related to aging. As noted by Lofaro and Subudhi (1993), many of the LERs are associated with administrative or procedural events that are typically non-aging events and not reportable to NPRDS. The NPRDS data were also evaluated in terms of component contribution. Of the components considered, without normalizing data to account for population effects, circuit breakers and blowers ranked first and last, accounting for, respectively, about one-third, and $10 \%$ of all fan cooler system failures.

Values for relative failure frequency, the relative frequency at which a particular component/ subcomponent fails, compared to other components/subcomponents in the system, were used to summarize aging characteristics. As part of this summary the frequency terms of "medium" and "low" were used based on the percentage of total occurrences. Frequency was termed "medium" if it was associated with $25 \%$ to $50 \%$ of the total and "low" if it represented less than $25 \%$. Briefly, component relative failure frequency for blowers is termed "medium" and further interpreted to mean that if a failure occurs in the fan cooler system, there is a "good" chance it will involve a blower. Moreover, if the failure does involve a blower, there is a "good" chance the failure will involve bearings. There is also a chance that either the shaft, rotors/blades, or belts will be involved; however, the relative failure frequency for these three subcomponents is termed "low."

The percentage of system failures related to aging determined from plant-specific fan cooler failure data was about $66 \%$. The data covered a 5 -year period for a system installed in a 16 -year-old pressurized-water reactor that uses five centrifugal fans. Fans accounted for about $10 \%$ of the system failures. These percentages are the same as or comparable to those developed from the database surveys.

\subsection{Failure Cause Analysis of Fans In Fossil-fuel Plants}

A third survey (EPRI 1981) describes a failure cause analysis for fans of fossil-fuel-fired power plants. A database of 701 centrifugal and 42 axial fans was developed, of which approximately $69 \%$ had experienced problems ranging from recurring maintenance to catastrophic failure. Obviously, the fan-operating environment of fossil plants can be more severe than that of nuclear reactors. Many of 
the fossil-fuel-fired plant fans, primarily induced-draft fans, including scrubber boosters, and a much smaller number of gas recirculating fans, are subjected to moisture and acid, large thermal variations, and fly-ash in high-velocity gas streams.

In terms of "direct causes," $13 \%$ of the centrifugal fan problems were categorized as "unknown/ normal wear." Over half of the centrifugal fan problems attributed to "unknown/normal wear," 49 of 91, were associated with forced-draft fans that supply ambient air for combustion. Erosion caused the greatest number of problems for centrifugal fans, about $20 \%$. Almost $80 \%$ of erosion problems were associated with the induced-draft fans that draw gas from the furnace. The normal location of the induced-draft fans is downstream from the pre-heater and electrostatic precipitator. It should also be noted that "...a number of the erosion problems were considered normal wear...[and] occurred over an extended period...". Vibration ranked second as a "direct cause" of centrifugal fan problems and was linked to erosion as well as several other factors. However, vibration problems were only $1 \%$ higher than the $13 \%$ categorized as "unknown/normal wear," the third highest cause. Components of centrifugal fans most frequently affected were bearings $(25 \%)$, blades $(17 \%)$, and foundations $(12 \%)$.

\subsection{DOE Experience With Aging Fans}

Although perhaps not directly applicable, DOE experience with aging ventilation exhaust fans should also be mentioned. Fan problems, primarily arising from bearing failure, have been reported for several facilities at the Rocky Flats Plant in Colorado. It is noted in Operating Experience Weekly Summaries that the "...problems experienced at these facilities underscore the increasing importance of surveillance testing and preventive maintenance on aging equipment throughout the DOE complex. Facilities should consider re-evaluating the testing and maintenance requirements for equipment exhibiting increased failure rates" (DOE 1993a, 1993b). 



\subsection{Fan Stressors, Aging Mechanisms, and Inspection, Surveillance, and Monitoring Methods}

This section of the report combines information about aging mechanisms, deleterious effects (aging degradation), and the various stressors that are involved. Techniques to detect degradation are also discussed briefly as part of a consideration of potential ISMM. As described below, stressors include mechanical, thermal, and environmental agents or stimuli; mechanisms range from fatigue to corrosion, possibly resulting in loss of rotor and shaft material strength and bearing seizure, respectively.

\subsection{Stressors and Aging Mechanisms}

Stressors are the agents that result from service conditions that can produce immediate or aging degradation. Stressors and the resulting negative aging effects that can impair fan performance are listed in Table 4.1 for selected components. In the case of fans, the major mechanical stressor is believed to be vibration. Thermal stressors include heat and abnormally high or low temperature. The term "environmental" is used to represent both physical and chemical agents or stimuli as well as radiation. High dust loading is an example of a physical agent. Chemical agents, including moisture, are the stressors that usually result in corrosion.

Also listed in Table 4.1 are the related aging mechanisms, the physical and chemical processes that gradually change component physical characteristics with time or use. The mechanisms range from wear and fatigue to erosion and corrosion.

Foundations were not included as a component because foundations and pedestals do not appear to be an aging issue in nuclear plants. Vibration could, of course, result in premature aging of foundations, but root cause of failure in this case would probably be a human error such as improper design, not aging.

\subsection{Inspection, Surveillance, and Monitoring Methods}

Many of the factors needed to ensure the reliable, trouble-free service of fans installed in nuclear systems are fairly evident: proper lubrication and cooling of fan shafts, couplings, and bearings and the alignment of fan bearings and couplings with the driving equipment (Babcock and Wilcox 1978). The importance of proper balance of fan wheels, both static and dynamic, is also emphasized. Fan reliability and maintenance is also discussed by Burchsted, Kanh, and Fuller (1976). Article BA-9000 of the Code on Nuclear Air and Gas Treatment specifies that fan manufacturers provide operating and maintenance manuals that include a recommended maintenance procedure along with a periodic servicing schedule (ASME/ANSI 1988). 
Table 4.1. Stressors, Aging Mechanisms, Aging Degradation, and Degradation Detection Methods for Selected Fan Components

\begin{tabular}{|c|c|c|c|c|}
\hline Fan Component & $\begin{array}{l}\text { Stressors (also } \\
\text { see text) }\end{array}$ & Aging Mechanisms & Aging Degradation & $\begin{array}{l}\text { Degradation Detection } \\
\text { Method(a) }\end{array}$ \\
\hline \multirow[t]{3}{*}{ bearings } & $\begin{array}{l}\text { mechanical: } \\
\text { vibration }\end{array}$ & wear & seizure & \multirow{3}{*}{$\begin{array}{l}\text { visual. } \\
\text { functional test. } \\
\text { vibration noise }\end{array}$} \\
\hline & $\begin{array}{l}\text { thermal: heat, } \\
\text { high temperature }\end{array}$ & $\begin{array}{l}\text { lubricant } \\
\text { degradation }\end{array}$ & seizure & \\
\hline & $\begin{array}{l}\text { environmental: } \\
\text { dust. moisture }\end{array}$ & $\begin{array}{l}\text { lubricant } \\
\text { degradation. } \\
\text { corrosion }\end{array}$ & seizure & \\
\hline \multirow[t]{2}{*}{ rotor } & $\begin{array}{l}\text { mechanical: } \\
\text { vibration }\end{array}$ & wear, fatigue & $\begin{array}{l}\text { loss of function/ } \\
\text { material strength }\end{array}$ & \multirow{2}{*}{$\begin{array}{l}\text { visual, } \\
\text { functional test. } \\
\text { disassembly }\end{array}$} \\
\hline & $\begin{array}{l}\text { environmenta 1: } \\
\text { dust }\end{array}$ & erosion & $\begin{array}{l}\text { pitting. loss of } \\
\text { function }\end{array}$ & \\
\hline shaft & $\begin{array}{l}\text { mechanical: } \\
\text { vibration }\end{array}$ & wear. fatigue & $\begin{array}{l}\text { cracking. loss of } \\
\text { function/material } \\
\text { strength }\end{array}$ & $\begin{array}{l}\text { functional test. } \\
\text { disassembly }\end{array}$ \\
\hline \multirow[t]{3}{*}{ belts } & $\begin{array}{l}\text { mechanical: } \\
\text { vibration }\end{array}$ & $\begin{array}{l}\text { wear. } \\
\text { deterioration }\end{array}$ & $\begin{array}{l}\text { cracking. loss of } \\
\text { function/material } \\
\text { strength }\end{array}$ & \multirow{3}{*}{$\begin{array}{l}\text { visual, } \\
\text { functional test. } \\
\text { (a) Methods taken from } \\
\text { Lofaro and Subudhi } \\
\text { (1993) }\end{array}$} \\
\hline & $\begin{array}{l}\text { thermal: heat. } \\
\text { high temperature }\end{array}$ & deterioration & $\begin{array}{l}\text { cracking, loss of } \\
\text { function/material } \\
\text { strength }\end{array}$ & \\
\hline & $\begin{array}{l}\text { environmental: } \\
\text { dust. } \\
\text { radiation }\end{array}$ & $\begin{array}{l}\text { wear. } \\
\text { deterioration }\end{array}$ & $\begin{array}{l}\text { cracking. loss of } \\
\text { function/material } \\
\text { strength }\end{array}$ & \\
\hline
\end{tabular}

ISMMs that will detect irregularities arising from improper lubrication, cooling, alignment, and balance of the various subcomponents should aid in counteracting many of the aging effects that could impair fan performance. Degradation detection methods listed by Lofaro and Subudhi (1993) for bearings include visual inspection, functional testing, and measurements of vibration and excessive noise. In addition to the functional test, disassembly inspection is suggested for shafts and rotors/ blades while visual inspection is recommended for rotors/blades and belts. These detection methods are also listed in Table 4.1.

Only one surveillance test was mentioned in the standards that were reviewed. Recommended frequency for this surveillance test, for airflow capacity, is presented in ASME N510-1989 (ASME 1989b). It is noted that airflow capacity tests for surveillance purposes are performed before any inplace leak testing. Recommended frequency for the in-place leak tests includes after filter/adsorber replacement and once each operating cycle. The airflow capacity test includes starting the system fan and verifying stable operation for 15 minutes. 


\subsection{Conclusions}

The results of this preliminary aging assessment suggest that aging degradation is an important factor in fan failure. Failure surveys containing information about aging and wear effects imply that about half of the failures reported for fans are primarily related to aging. Aging mechanisms associated with the various fan components and resulting from mechanical, thermal, and environmental stressors include wear, fatigue, corrosion, and erosion of metals and the deterioration of belts and lubricants. A bearing is the component most frequently linked to fan failure. The assessment also suggests that ISMM that will detect irregularities arising from improper lubrication, cooling, alignment, and balance of the various components should aid in counteracting many of the aging effects that could impair fan performance.

The observation that aging degradation appears to be an important factor when considering fan failure, reinforced by the fact that failure can impact both plant and public safety, suggests the need to expand the preliminary study. As indicated above, there appear to be ISMM that conceivably can alleviate aging effects. The focus of any expanded program would be to further define and identify current ISMM and maintenance practices, evaluate their adequacy, and provide preliminary recommendations for improvements. Performance parameters and condition indicators potentially useful in detecting degradation would also be identified. It is expected that the work would be accomplished primarily by vendor and utility contacts, visits, and/or surveys. One or more consulting subcontracts with operation and maintenance experts are also anticipated. Initially, the experts would be asked to provide external peer review of this preliminary assessment and provide their opinions about the need for and scope of any expanded program. The results of the expanded effort would ultimately be combined with those of this preliminary study in the form of a Phase I interim aging assessment published as a NUREG report. 



\subsection{References}

10 CFR 50. 1992. U.S. Nuclear Regulatory Commission, "Domestic Licensing of Production and Utilization Facilities." U.S. Code of Federal Regulations.

Air Movement and Control Association, Inc. (AMCA). 1985. Fans and Systems, Fan Application Manual. Publication 201, Arlington Heights, Illinois.

Air Movement and Control Association, Inc., and American Society of Heating, Refrigeration and AirConditioning Engineers, Inc. (AMCA/ASHRAE). 1986. Laboratory Methods of Testing Fans for Rating. ANSI/AMCA 210-85, ANSI/ASHRAE 51-1985, Arlington Heights, Illinois, and Atlanta, Georgia.

American Society of Mechanical Engineers (ASME). 1989a. Nuclear Power Plant Air-Cleaning Units and Components. ASME Standard N509-1989, New York.

American Society of Mechanical Engineers (ASME). 1989b. Testing of Nuclear Air Treatment Systems. ASME Standard N510-1989, New York.

American Society of Mechanical Engineers/American National Standards Institute (ASME/ANSI). 1988. Code on Nuclear Air and Gas Treatment. ASME/ANSI AG-1-1988, New York.

Babcock and Wilcox. 1978. Steam, Its Generation and Use. New York.

Burchsted, C. A., J. E. Kahn, and A. B. Fuller. 1976. Nuclear Air Cleaning Handbook. ERDA 76-32, Oak Ridge National Laboratory, Oak Ridge, Tennessee.

DOE. 1993a. Operating Experience Weekly Summary 93-6 (February 5 - February 11, 1993). U.S. Department of Energy, Office of Nuclear Safety, Washington, D.C.

DOE. 1993b. Operating Experience Weekly Summary 93-8 (February 19 - February 25, 1993). U.S. Department of Energy, Office of Nuclear Safety, Washington, D.C.

Electric Power Research Institute (EPRI). 1981. Failure Cause Analysis - Fans. EPRI CS-1693, prepared by Fan Systems Company for EPRI, Palo Alto, California.

Electric Power Research Institute (EPRI). 1992. Nuclear Power Plant Common Aging Terminology. EPRI TR-100844, prepared by MPR Associates, Inc. for EPRI, Palo Alto, California.

Lofaro, R., and M. Subudhi. 1993. The Effects of Age on Nuclear Power Plant Containment Cooling Systems. NUREG/CR-5939, U.S. Nuclear Regulatory Commission, Washington, D.C.

Meale, B. M., and D. G. Satterwhite. 1988. An Aging Failure Survey of Light Water Reactor Safety Systems and Components. NUREG/CR-4747, Vol. 2, U.S. Nuclear Regulatory Commission, Washington, D.C. 
NRC. 1978. Design, Testing, and Maintenance Criteria for Post Accident Engineered-Safety-Feature Atmosphere Cleanup System Air Filtration and Adsorption Units of Light-Water-Cooled Nuclear Power Plants. Regulatory Guide 1.52, U.S. Nuclear Regulatory Commission, Washington, D.C.

NRC. 1979. Design, Testing, and Maintenance Criteria for Normal Ventilation Exhaust System Air Filtration and Adsorption Units of Light-Water-Cooled Nuclear Power Plants. Regulatory Guide 1.140, U.S. Nuclear Regulatory Commission, Washington, D.C.

NRC. 1991. Nuclear Plant Aging Research. NUREG-1144, Rev. 2, U.S. Nuclear Regulatory Commission, Washington, D.C. 


\section{Distribution}

No. of

Copies

OFFSITE

25 U.S. Nuclear Regulatory Commission Washington, D.C. 20555

ATTN: S. K. Shaukat (20)

$$
\text { J.P. Vora }
$$

R. L. Lofaro

Brookhaven National Laboratory

Upton, NY 11973

D. G. O'Conner

Oak Ridge National Laboratory

P.O. Box 2009

Oak Ridge, TN 37831

L. Magelby

Idaho National Engineering Laboratory P.O. Box 1675

Idaho Falls, ID 83415
No. of

Copies

S. P. Nowlen

Sandia National Laboratory

P.O. Box 5800

Albuquerque, NM 87185

ONSITE

DOE Richland Operations Office

D. C. Langstaff

K8-50

19 Pacific Northwest Laboratory

M. E. Cunningham (10)

$\mathrm{K} 8-43$

A. B. Johnson

K8-34

J. V. Livingston

K8-37

R. D. Orton

K8-33

Publishing Coordination

K1-06 
